Please quote as: Elshan, Edona; Engel, Christian \& Ebel, Philipp: Opening the Black Box of Music Royalties with the Help of Hybrid Intelligence. 2021. - Hawaii International Conference on System Sciences (HICSS). - Kauai, USA. 


\section{Opening the Black Box of Music Royalties with the Help of Hybrid Intelligence}

\author{
Edona Elshan \\ University of St.Gallen, St. Gallen \\ edona.elshan@unisg.ch
}

\author{
Christian Engel \\ University of St.Gallen, St. Gallen \\ christian.engel@unisg.ch
}

\author{
Philipp Ebel \\ University of St.Gallen, St. Gallen \\ philipp.ebel@unisg.ch
}

\begin{abstract}
The ever-increasing complexity of the music industry and the intensified resentment of artists towards collecting societies call for a transformation and a change of behavior within the music ecosystem. This article introduces a hybrid intelligence system, that ameliorates the current situation by combining the intelligence of humans and machines. This study proposes design requirements for hybrid intelligence systems in the music industry. Using a design science research approach, we identify design requirements both inductively from expert interviews and deductively from theory and present a first prototypical instantiation of a respective hybrid intelligence system. Overall, this shall enrich the body of knowledge of hybrid intelligence research by transferring its concepts into a new context. Furthermore, the identified design requirements shall serve as a foundation for researchers and practitioners to further explore and design hybrid intelligence in the music industry and beyond.
\end{abstract}

\section{Introduction}

According to PricewaterhouseCoopers ( $\mathrm{PwC})$, the live music industry (i.e., concerts and festivals) was projected to generate $\$ 28.8$ billion in 2020 [23] ultimately, the global pandemic cancelled that. By virtue of the numerous cancellations of festivals and concerts [e.g., 1, 4], an essential and substantial part of the acquisition for artists is lost. It must not be neglected that for many artists, concerts are the primary source of income and account for up to 75 percent of their income [35]. Although this unequal distribution of income sources has been known for some time, the events of the last few months have exacerbated the situation and led to the fact that many artists have no source of income.

This problem is further increased by the fact that right holders (e.g., artists or songwriters) wait up to two years before they receive remuneration for the use of their work [29]. However, it is not only the delay of the remuneration that causes problems but also the actual payment of the usage leads to dissatisfaction. Every year, the use of musical works of 2.5 billion dollars remains unknown [5]. Considering the ever-increasing hours of music streamed per week, it appears surprising that artists are not raising a considerable amount of money out of streaming services. Nevertheless, the industry is benefitting from the streaming music; except these benefits are not entirely being passed to the artists, even though they are typically the first to put in an effort [22].

This is incredibly painful for niche artists, who have a small share of the cake, because the revenues, which cannot be assigned to a specific use, are distributed based on turnover [27]. This logic leads to the fact that artists, who are often heard in any case, take in an even more prominent place at the table than they already do.

The origin of this problem lies primarily in the unfavorable data management of a sound recording's meta-data, which makes it more or less impossible to establish common international standards [22]. This unsatisfying situation has arisen due to the fact that the music industry has a stormy relationship with technological advancements. On the customer-facing side, the music industry has undergone a digital transformation. Napster made the first steps in the digital transformation of music consumption by establishing a platform for the exchange of music. This was followed by the era of downloading and purchasing music on portable digital media players (e.g., iPod). Finally, Spotify stepped into the shoes of Napster by shifting the customer's need from owning music to streaming it.

Nevertheless, things look different behind the scenes. The backbone of the music industry is obsolete as technological change outpaced the backend, and the stakeholders were not able to adapt to these changes. Amongst other factors, the obsolete backbone is the reason why collecting societies are accused of working inefficiently. From this point of view, it seems to make sense to consider how efficiency and transparency can be brought to the exploitation of musical works. There exist different possibilities to address this problem. Potentially the issues could be tackled by the introduction of a blockchain-based application. 
Although there are many companies (e.g., Kobalt Music) that aim to address the issues with the mentioned approach, the intransparency still remains. Another possible approach to opening the black box is the application of artificial intelligence. In our understanding, artificial intelligence systems are such that are able to perform "activities that we associate with human thinking, activities such as decision-making, problem solving, learning" [2].

There has been a broad consensus that artificial intelligence has the potential to deliver substantial economic benefits and could be used to a wide array of application fields [15]. Notwithstanding computers are not able to distinguish specific performer (i.e., background singer a, that participated in the tour of 2018 from background singer $\mathrm{b}$, that took part in the tour of 2019). Up to now, machines are not trained to "listen" to music the way humans would and therefore are not in the position to unleash the value trapped in the black box solely without the help of human intelligence. Such human-in-the-loop approaches are incredibly valuable when only little data is available, pre-trained models need to be adapted for specific domains, the stakes are high or in contexts where human annotations are already used without teaching it to a machine. Even though the data available is being improved, many recordings lack meta-data. Therefore, this research paper focuses on how machines and humans can open the black box of music royalties together. The engagement of humans into the decision process of artificial intelligence systems is widely acknowledged in research and practice [16, 31]. The case under consideration represents another context in which algorithms and humans have to work closely together in order to create value for third parties (i.e., artists). To explore this matter, we ask the following research question:

How should a hybrid intelligence system be designed to unleash the value trapped in the black box of music royalties?

To answer this question, the remainder of this paper is structured as follows. In the next section, we provide an overview of the music industry and its stakeholders and introduce the concept of hybrid intelligence. Then we describe our design science research approach. The following section consists of the design and evaluation of design requirements for a hybrid intelligence system. Our paper will conclude with the limitations and implications for research and practice and a short summary of the results.

\section{Theoretical and Conceptual Background}

\subsection{Hybrid Intelligence}

The term of the Hybrid Intelligence [7] describes the interplay of artificial and human intelligence to achieve together a higher performance than each of the individual entities could achieve alone. Thus, hybrid intelligence allows distributing computational tasks to human intelligence on demand (e.g., when artificial intelligence is uncertain) to minimize shortcomings of current artificial intelligence systems. Such human-inthe-loop approaches are particularly valuable when only little data is available to date, pre-trained models need to be adapted for specific domains when the stakes are high, there is a high level of class imbalance, or in contexts where human annotations are already used without teaching it to a machine. The basis of every hybrid intelligence system is an artificial intelligence that performs a predefined task based on a predefined set of data. Whenever these prerequisites are not given, a human helper comes into play, in order to assist the artificial intelligence at hand.

In the course of the presented case, the human part of intelligence finds its way into hybrid intelligence through the participation of a crowd. The fundamental concept of a crowd suggests that a prior undefined group of contributors (e.g., individuals, formal or informal teams, other companies) engages voluntarily in a task that is presented in an open call [3]. Further, it has to be determined who should be able to join the crowd. During the crowd construction, decision-makers should specify if anyone should have access or only a specific type of selected participants [20].

This human intelligence, in the form of a crowd, constitutes the second element of a hybrid intelligence system. The third element is a digital platform on which human and machine interact with each other. Due to the close relationship between the three elements, hybrid systems can, therefore, be understood as socio-technical systems. According to Kittur et al. [17], such sociotechnical systems can be defined as systems in which individuals, technologies and work activities are interlinked. In this regard, hybrid intelligence systems constitute an open working system, within which human participants perform work (generating input for artificial intelligence) and deliver the product of their work to another actor (artificial intelligence).

\subsection{The Value Network of the Music Industry}

The "producing" side of the music industry is a value network with many different stakeholders. In order to gain a better understanding of the industry and 
its underlying challenges, we have to understand the ecosystem and its value streams. As depicted in Figure 1, we have two different stakeholders for artists and songwriters. These circumstances are accounting for the complexity. There are two different kinds of copyrights to monetize: one for the sound recording (recorded performance) and one for the musical work (underlying words and music). These two stakeholders may be the same person but do not have to be. In other words, this means a song might be written by the artist that performs it. For instance, Yesterday by the Beatles was written by John Lennon and Paul McCartney (both from The Beatles) but also performed by many others, e.g., Boys II Men. In the case that the songwriter does not perform the track composed, they will have a publishing contract [34].

While publishing companies, take care of the release of a composition, producers take care of the production of the sound recording. Again, it should be noted that the stakeholder "Producer" can be occupied by the same person as the "Artist". market: Sony BMG, Universal Music Group and Warner Music Group. The rest of the market share is distributed among independent labels.

An additional and vital stakeholder is the copyright collective, also known as PROs (performance right organizations). Their function within the ecosystem is central as they are responsible for tracking and the collection of royalty payments.

On the " consumption side " various services exist; in principle, these can be divided into performancebased (e.g., streaming) and non-performance-based (physical retailers).

In summary, a sound recording usually will be monetized by the record label and is created by the artist and/or performer; whereas a musical composition is created by songwriters and lyricists and monetized by music publishers [22].[26]

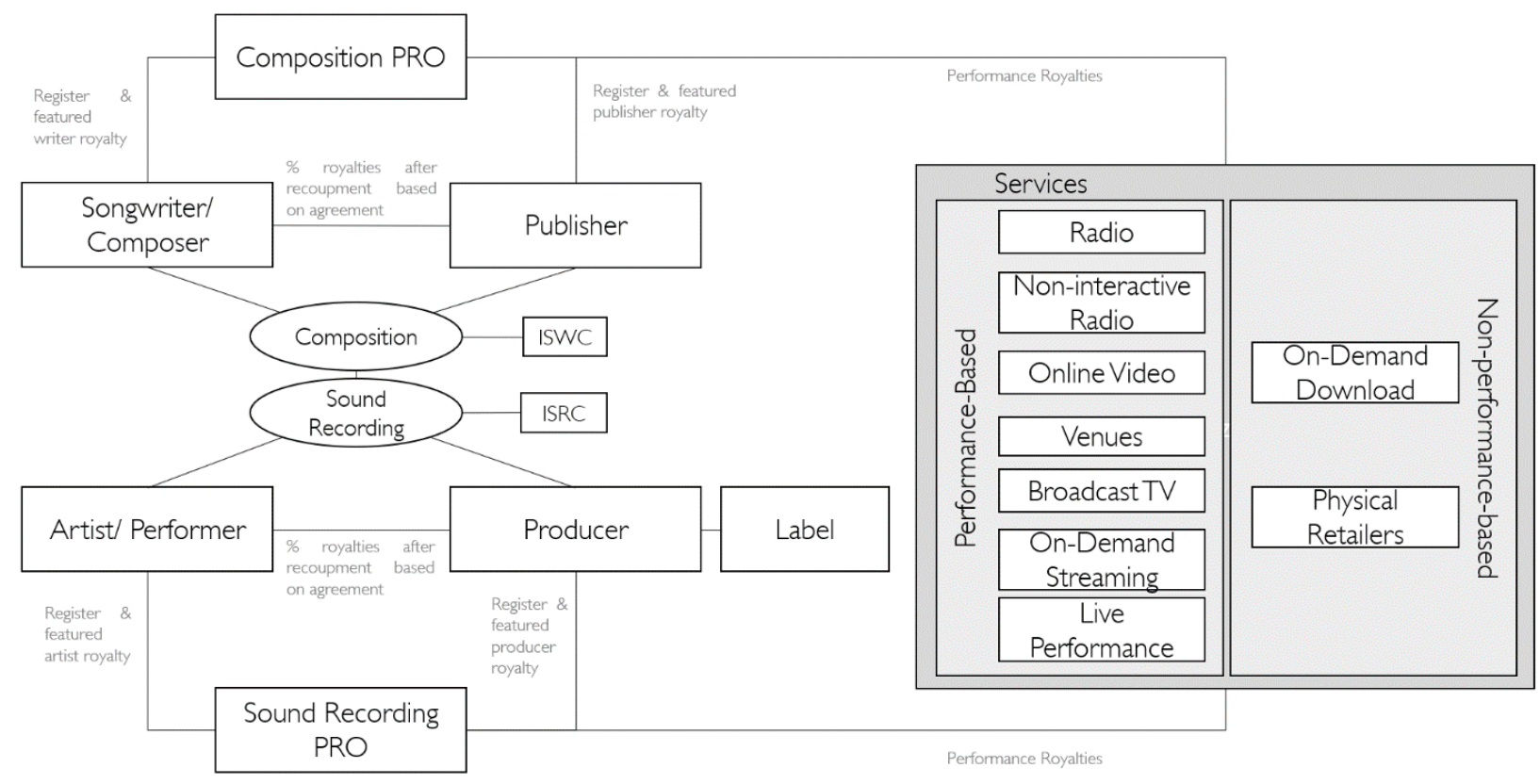

Figure 1. Musical Network based on Sitonio and Nucciarelli [25]

Another important stakeholder is the label. Usually, labels interact as an intermediary in various areas within the value chain: production, distribution, as well as promotion [28]. This strong position within the ecosystem is one of the reasons why labels have such a significant influence [25]. This balance of influence is increasingly being reinforced by the fact that there are only three major labels that occupy a large part of the

\section{Research Design}

In order to answer our research question, we based our research approach on the design science research (DSR) paradigm [11], since our objective is to solve a design problem experienced by many stakeholders within the music industry, in particular, to enhance the value capturing within the industry. The bottom-line to 
DSR is to build an artefact-based theory and/or empirically derived design principles to generate design knowledge and theoretical insights. Therefore, we chose this approach because we intend to a) contribute to the existing body of knowledge by designing and evaluating a new research artefact and documenting our design knowledge according to Gregor and Jones [12] and b) use a scientific method to solve a set of practical problems. We base our research approach on the DSR framework by Hevner [14], which consists overall of three design cycles Figure 2 shows the steps that have been carried out as well as their order and the corresponding subchapters within this paper.

The first step includes the problem formulation. The practice-driven motivation of the problem was discussed in detail in the introduction chapter. In the second step, we start the rigor cycle, where we gather requirements from different theoretical perspectives. In the third step, we initiate the relevance cycle by deriving requirements from expert interviews. In the fourth step, we launch the design cycle by formulating the initial set of requirements for the hybrid intelligence system. In the fifth step, we conduct the first evaluation of our alpha version with the help of expert interviews. The reason for this evaluation is the assurance that we capture the essential requirements and logically translate them into design requirements [30]. Subsequently, the refinement will be executed in the sixth step. Afterwards, we instantiate the hybrid intelligent system with the help of a pilot study in the music industry in the seventh step.

To achieve both rigor and relevance, researchers have to go "the last research mile". This last research mile consists of three steps, and the goal is to solve the dilemma between rigor and relevance [21]: (i) proof-ofconcept-research, (ii) proof-of-value-research and (iii) proof-of-use-research. In accordance with Nunamaker et al. [21] proof of concept research identifies the relevant problem (i.e., lack of transparency in the music industry) and presents the feasibility of a solution. It must be mentioned that within this paper, we only do focus on the proof-of-concept. Therefore, the proof-ofvalue-research and proof-of-use-research will be out of

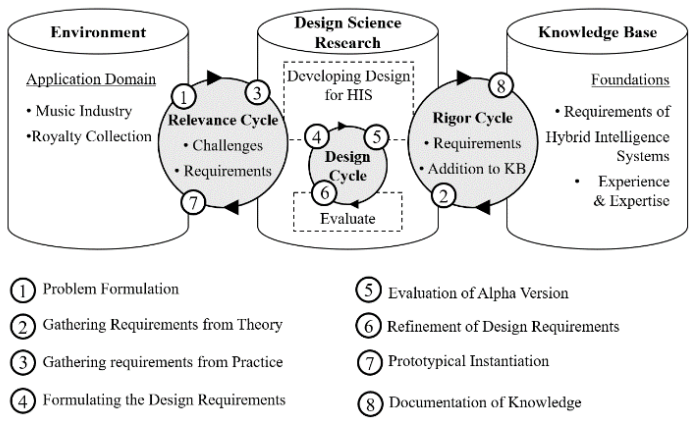

Figure 2. Research Approach the scope of this paper but we urgently stress the importance of the latter for truly designing for utility in use. Thus, we propose these as necessary steps for future research.

\section{Designing a Hybrid Intelligence System}

In the following chapter 4 , we describe the design process of the hybrid intelligence system for the music industry. Every subsection refers to one of the corresponding steps visualized in Figure 2.

\subsection{Deriving Requirements from Literature - Addressing important Aspects of the Music Industry}

In this section, we derive requirements from literature for the fundamental development of the hybrid intelligence system. In order to understand, how hybrid intelligence may contribute to capturing value within the value chain, we have to shed light on the different issues that cause a complicated situation that can be solved neither solely through technology nor solely through humans.

Intending to identify current research and issues in the field of our topic, we conducted a literature review [33]. We examined the main research streams dealing with the problems within the music industry. This is the core element to first get a broad knowledge of the industry and second get an understanding of how to adapt and evaluate the proposed solution.

For our literature review, we chose rather general search terms which included "music industry, "digitalization", "digital transformation" or "digitization". We did this intending to gain a broad overview of the topic. Our search was limited to publication title, abstract and keywords. Further, we only included literature of the last ten years, as we aimed to identify current issues. The literature review was primarily conducted on Google Scholar in order to identify literature from a wide range of academic disciplines, which is aligned with the interdisciplinary nature of our research topic. Our first search resulted in 345 articles, with the help of our inclusion and exclusion criteria, our end sample resulted in 14 relevant articles. We did not include papers that represented calls, editorials or forewords. In addition to that, articles that dealt with the digital transformation in general, were not included. Only papers that were investigating the music industry were included.Further, we did exclude literature that focused on the digital transformation of the end-consumer. In the following, we will discuss the various challenges and their roots and derived requirements for a hybrid intelligence system. 
One of the biggest challenges is the lack of governance in copyright law [34] (Issue 1). For most of the time, collecting societies (PROs) are unable to administer the earnings to another country if the involved country does not own a reciprocal agreement [9]. This issue comes with another one: collecting societies do not have a unified database (Issue 2). Even though different standards do exist (e.g., ISRC or ISWC), they could not establish within the industry (Issue 3). The lack of a common database leads to another difficulty: royalties end up being trapped within the collecting societies (also known as black box money).

The root of this problem is the loss of data due to the fact that PROs tend to suppress part or all of the data confidential [9]. Therefore, the system is often unable to determine who the correct right holder is (lack of knowledge of whom to pay, Issue 4). In the worst case, the system has incorrect licensing information, and the profits are being paid out to an inaccurate artist or songwriter (Issue 8).

However, there is an additional challenge if data is being kept secret: an artist might not be earning anything out of their music. Stems from the fact that the copyright law is flexible non-disclosure agreements might contain unfavorable information (Issue 5). The most prominent example was the leak of Lady Gaga's contract in 2014. In that, it was stated that Interscope Records would not pay anything to Lady Gaga on licensing deals that involve the entire label catalog [24]. These kinds of circumstances lead to artists not knowing what they are making out of their work (Issue 6). In the past, this has resulted in them taking their albums and singles off a platform (e.g., Taylor Swift's new albums were not on Spotify [32], Jay-Z's music was not on Spotify up to 2019 [13], Prince's music was not on Spotify nor Apple Music up to the end of 2017 [4]).

Nevertheless, not only artists have taken the music from platforms, but in the past, there were also cases in which a PRO is switched on like it was the case with GEMA and YouTube [36]. However, in this case, the motives were slightly different; namely, GEMA demanded the compensation of copyrights from the streaming platform and started a legal case [18] (Issue 7).

The most frequently encountered phenomenon is black box money. As mentioned, collecting societies sometimes cannot allocate the benefiter royalties due to different issues (e.g., when the recording is missing because it is not listed in the playlist of radios). In this case, there is no clear stream for the value (i.e. royalties) to flow, and the benefit gets stuck with the collecting society [27]. This matter is often a taboo that only a few people dare to speak about [19]. The failure of the system to identify the correct right holder is up to now a sore and sensitive point. In the case of Switzerland, the money that cannot be distributed due to the inability to determine the right holder is being distributed based on a representative sample of radios of Switzerland. These circumstances lead to the fact that artists that are not that famous or strongly represented are being penalized and treated disadvantageously. For instance, imagine a radio that only plays music by a single Swiss niche artist. If the radio fails to deliver the list of played music (e.g., incomplete or non-existent) to the collecting societies, the revenue will not be paid out to that Swiss niche artist but to the artist that is being played the most pro-rata even though most of the black box money will at some point be redistributed to an artist. It will not get entirely stuck with the collecting societies.

\section{Table 1. Challenges within the Music Industry}

\begin{tabular}{|l|}
\hline \multicolumn{1}{|c|}{ Identified Issues } \\
\hline Issue 1: Lack of Governance in Copyright Law \\
\hline Issue 2: Lack of Unified Databases \\
\hline Issue 3: Lack of Standardized Formats for Meta-Data \\
\hline Issue 4: Lack of Knowledge \\
\hline Issue 5: Lack of Transparency \\
\hline Issue 6: Lack of Compensation \\
\hline Issue 7: Lack of Willingness to Pay \\
\hline Issue 8: Black Box Money \\
\hline
\end{tabular}

Our literature review shows the various issues and problems that exist within the music industry. The major issues were the lack of governance in copyright law, the lack of unified databases, the lack of standardized formats for meta-data, the lack of transparency as well as the lack of compensation. These findings show that a proposed solution has to tackle most of these problems in order to enhance the value capturing within the industry.

From this point, the following meta requirements can be derived: The first meta-requirement (MR1) deals with the exchange of knowledge and data to ameliorate the databases and knowledge (I2, I4). Whilst the second meta-requirement (MR2) points out the importance of standardized procedures to capture information in an effective and efficient way (I3, I5). In the third metarequirement (MR3) the hybrid intelligence system is intended to ensure that a creator (artist, songwriter, producer) is compensated adequately for its work (I1, I6, I7, I8). 


\subsection{Deriving Requirements from Expert Interviews}

In order to derive requirements from practice, we conducted qualitative empirical interviews [8]. We followed a three-step procedure:

Initially, we selected potential interview partners based on our contacts from practice projects. Consequently, we interviewed experts of the music industry who also deal with current topics and issues. These experts were also qualified to observe and discuss the solution in their strengths and weaknesses. It must be noted that the participant consists almost entirely of Swiss experts. In a nutshell, the sample group is capable of: (i) assessing the current situation and evaluating how the hybrid intelligence system may enhance the value creation within the music ecosystem and (ii) understanding the consequences and risks of the implementation of such an approach. To ensure heterogeneity and achieve a complete picture, we included various stakeholders of the music industry as our experts. Thus, we want to derive requirements that apply for all of the stakeholders within the ecosystem and is not biased for a specific stakeholder's view. The following table gives an overview of the participants.

Table 2. Interview Information

\begin{tabular}{|l|l|l|}
\hline ID & Position & Stakeholder Group \\
\hline INT01 & Head of IT & $\begin{array}{l}\text { Collecting Society } \\
\text { (writer and publisher } \\
\text { royalties) }\end{array}$ \\
\hline INT02 & $\begin{array}{l}\text { Executive } \\
\text { Management }\end{array}$ & $\begin{array}{l}\text { Collecting Society (artist } \\
\text { and producer royalties) }\end{array}$ \\
\hline INT03 & $\begin{array}{l}\text { Executive } \\
\text { Management }\end{array}$ & Indie Label \\
\hline INT04 & Manager & Artist and Producer \\
\hline INT05 & Attorney & Copyright Attorney \\
\hline INT06 & Advisor & $\begin{array}{l}\text { Representatives of } \\
\text { interest }\end{array}$ \\
\hline INT07 & Advisor & Label \\
\hline INT08 & $\begin{array}{l}\text { Managing } \\
\text { Director }\end{array}$ & $\begin{array}{l}\text { Federation of the } \\
\text { Phonographic Industry }\end{array}$ \\
\hline INT09 & Artist & Artist \\
\hline INT10 & Advisor & Publisher \\
\hline
\end{tabular}

We conducted the interviews online via a video conference tool on a timeline ranging from April to June 2020. In accordance with the theoretical saturation by Glaser and Strauss [10], we terminated our search for further industry experts when no new insights were disclosed. The interviews were recorded and afterwards transcribed. Lastly, we analyzed and coded our transcripts by using a structured content analysis.
The interviews revealed that a hybrid intelligence approach might satisfy the needs of various stakeholders within the music industry. It was mentioned several times that merely the introduction of an all-inclusive platform would already be of great assistance (UR1):

"In any case, the compensation does not work the way you want it to at the moment. We currently have significant deficits when it comes to working together." (INT03)

Additionally, it was mentioned that the monitoring might be ameliorated by the introduction of a hybrid intelligence approach, e.g., with the application of dashboards (UR2).

"I think that monitoring is still somewhat incomplete today." (INT02)

Not only shall the system consider the monitoring, but it should also take into account that the industry is currently lacking transparency (UR3). Therefore, it is essential that the proposed solution reflects this requirement.

"I wish that with the application of this solution, the lack of transparency would be minimized." (INT04)

Another requirement addressed the speed of tracking and assigning copyrights (UR4). Since today it takes up to two years until a copyright holder receives the compensation, the newly introduced solution shall be faster and more efficient.

"With such an approach, it would be fairly easy to collect the money directly and distribute it quickly." (INT07)

Further, it was mentioned that the quality of the data must be right in order for a musical work to be tracked completely. It can be deduced from this that control mechanisms are necessary to keep quality high and should, therefore, be considered in the design of the artefact (UR5). In addition to that, some consider especially the coverage of niche artists to be problematic.

"The coverage in the broad mass is the problem. If someone succeeds in covering niche channels better, they will create a high added value." (INT09)

\subsection{Deriving Design Requirements for the Alpha Version}

Based on the requirements from literature and practice, we describe below what the design of a 
potential hybrid intelligence system for enhancing value capturing in the music industry would require.

\section{Table 3. Design Features}

\begin{tabular}{|l|}
\hline Design Features for Hybrid Intelligence System \\
\hline Design Feature 1: \\
Continuous and Aggregated Display of Tracking \\
and Monitoring \\
\hline Design Feature 2: \\
Efficiency and Speed Enhancing Components to \\
foster the cooperation between Humans and \\
Machine \\
\hline Design Feature 3: \\
Inclusion of Control Mechanisms by the Human-in- \\
the-Loop \\
\hline Design Feature 4: \\
Interactive Feedback Cycle Between Humans and \\
Machine \\
\hline
\end{tabular}

The first design feature (DF1) specifies that the collected data should be made visually available in the form of dashboards on different levels, i.e. individual level for one single artist or aggregated level for producers. The dashboard should indicate the total of tracked consumption, potential differences and gaps as well as the actual revenue (per used copyright and/or aggregated). By implementing this first design requirement, reflection and understanding can be promoted. During the interviews, it was mentioned that the possibility to assess the current tracking and being able to display the consumption and potential revenue would be of great interest. Additionally, a historical display of the consumption overtime is needed to make the payout transparent and visible. This allows the artist to track the success of its work and think about changes that can be made (e.g., concert in country A, due to a more considerable fanbase). Further, the display of tracking and monitoring of copyrights contributes to the managements analyzing the gaps between the potential revenue and the paid out one. Therefore, this aggregated insight serves as a starting point.

The second design feature (DF2) takes into account the importance of efficiency and speed. In order to add the most significant value, the hybrid intelligence system shall present all of the data in real-time. Normally the consumption will be tracked and evaluated in real-time. Only in exceptional cases would an immediate identification not take place. However, this is also an improvement on the current situation.

The third design feature (DF3) derived for the alpha version defines that the inclusion of control mechanisms that can verify the correctness, assess the quality and formulate measures if part of the hybrid intelligence system does not meet the expectations.
The fourth design feature (DF4) describes the importance of feedback to facilitate the correctness of the allocated royalties. An important property of the artefact to be designed is to provide an interface where exchange and feedback loops between the machine and human take place. This is the only way to ensure that the machine learns from human input and vice versa.

\subsection{Evaluation and Refinement}

According to Sonnenberg and vom Brocke [30], it is crucial to direct the foci of evaluations on two aspects: (1) the constituents of the artefact and the design decisions take as well as on (2) the evaluation of the usefulness of the artefact [33]. Thus, the first evaluation of our proposed design focuses on the constituents of the artefact and our design decisions. The purpose of the evaluation is to ensure the completeness and the correctness of the different steps as well as to clarify if the expert would use the proposed artefact. We asked the same experts as in the previous step individually. First, we showed the design requirements and explained them to the experts. Second, we asked them to share their thoughts with us regarding the potential utility creation of such a design.

Experts that were analyzing the hybrid intelligence approach to enhance the value capturing expressed mainly positive opinions. Concerning the tracking and monitoring of copyright usages in real-time, the experts expressed that this would be a significant improvement in comparison to the current approach. Overall, the aspect of completeness and knowledge of data was considered positive. In Switzerland, for instance, only 25 radio stations are being tracked, and the usage of the others (around 2000 radio stations) will be calculated based on the usage of copyrights of these 25 representative stations. Further, it has to be mentioned that for the majority of the experts, it was of the utmost importance that the introduction of a hybrid intelligence approach also led to cost savings. Although this was not originally considered to be an important criterion, the feedback received has led to the proof of value being recorded. Through the efficient use of artificial and human intelligence, human resources can be saved and used elsewhere on the part of collecting societies. On the side of artists and songwriters, the use of hybrid intelligence will result in the liberation of new resources, which they could benefit from, since each dollar that does not have to be spent on tracking down the accurate right holder can, for the most part, be allocated to the right holders.

"The offer of such a system must also come to a much cheaper offer as if we would do it ourselves. We expect cost savings through the system." (INT01) 
However, it is essential that there is not only cost savings but also a value add. Accordingly, the following has been added:

"At the end of the day, we would like to see the additional money streams that have been uncovered." (INT10)

Taking up this observation, it needs to be emphasized that one advantage of the solution is that even if there is a machine malfunction (e.g. matching cannot be performed), a human being can verify and monitor the failure. In this particular scenario, the advantages of a hybrid intelligence approach are evident.

"Especially in classical music, the whole thing becomes particularly complex. If a piece is performed with an orchestra and the flutist A plays the piece and the flutist $B$ plays the other time in the recording, then the artificial intelligence should be able to recognize the difference. However, technology has not yet reached that point. At this point, the human ear is of help. In this way, the slightest differences can be recognized, and we can make the correct distribution." (INT02)

In addition to the derived requirements, the experts also commented on the changing roles within the music ecosystem and what changes this will have on the respective stakeholders if such an approach is introduced:

"It is questionable how strongly collecting societies will be required in the future, although it does not mean that they are completely gone, they are still very strong players who can build up negotiating power." (INT10)

"In my opinion, the designation "collecting society" is incorrect. The main task of these societies is distribution. Therefore, they shall be called 'distribution societies. In the future, they should focus on that part." (INT03)

"In the long term, collecting societies could take a position similar to that of banks." (INT07)

"I think that all participants in the current ecosystem will also be important in the future. some of the tasks may change somewhat, but all will still have meaning." (INT05)

It is vital that this shift is taken into account and addressed within the design of the artefact. Overall, it can be noted that the use of hybrid intelligence might enhance the value capturing within the music industry, taking into account some important factors.

\subsection{Prototypical Instantiation}

We instantiate our artefact with the help of a pilot study. Two Swiss collecting societies take part (one for artist's royalties, one for compositor's royalties) in evaluating the prototypical instantiation.

The pilot study aims to track and report to copyright holders so they can collect music royalties from radio stations, live performances and streaming services. With the help of the proposed system artists, collectors and labels can track the consumption of their music in realtime. The intention is to digitalize the music end-to-end. The hybrid intelligence system will do so by enabling the music data communication between the different industry stakeholders and taking on the role of an intermediary (as seen in Chapter 2.1). By doing so, it can be ensured that the systems become the preferred supplier of music data consumption insight across all platforms as well as channels.

In order to dissolve the challenge of black box money in the music industry and to apportion the generated revenue fairly and equitably, as well as to evaluate previously unknown sources of usage, an algorithm is used which tracks and evaluates radio stations, whether online or conventional. First, the algorithms will try to match the music track with the help of the metadata. For instance, it would verify if the combination of artist, title, year and venue is the same as the ones in the database. If the algorithm fails to do this, the audio matching will be conducted. This only works if there is a soundtrack of the song saved in the database. If this is not the case, as it might be a cover of a song, the task to identify the music will be handed over to human intelligence. With this undertaking, several concerns will be addressed simultaneously.

By establishing a database with all meta data relevant for the correct identification and distribution of the royalties, the hybrid intelligence system aims to resolve the lack of the unified database. Since no single stakeholder (neither collecting society A nor collecting society B nor label) controls the database but rather a third party, it can be considered as a decentralized system that leverages the wisdom of the crowd combined with machine intelligence. When the music of an artist and/or composer is being used, the usage is being recorded, and the corresponding royalties that have to distributed are registered in the database.

However, this project has an upstream step, which is that the meta data must first be fully complete; otherwise, the machine cannot recognize which musical composition is involved. This is where human intelligence comes into play. Unlike the computer, a 
human being can listen to the track and manually supplement the information missing. Nevertheless, this will not be the only task that human intelligence will handle. Besides, the human being will be assigned to monitor and verify the computer's evaluations and, if necessary, to amend them.

Furthermore, each musical work has to be captured and registered initially with the meta-data. It must be ensured that the formats of data storage are compatible with those of the collecting societies, as otherwise, the collecting societies cannot determine who the right holder is.

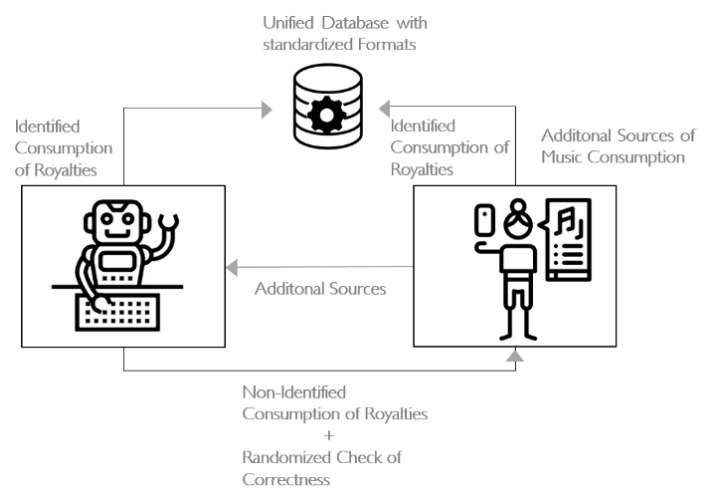

\section{Figure 3. Conceptual Instantiation of a Hybrid Intelligence System in the Music Industry}

\section{Limitation and Outlook}

Even though we carefully proceeded with our research, the presented analysis and evaluation is not free of limitations, and in line with the "last research mile", further research interest still arises. First, requirements for our design are derived from a specific field of research and a certain selection of experts. The requirements would likely be different if we had used different theoretical perspectives and interview partners. However, we tried to select the most relevant research field and a representative sample of stakeholders within the music industry to account for creating design-based utility. Further, this study focuses on a hybrid intelligence approach in one specific industry. Other industries might face different challenges, and thus a hybrid intelligence approach might not bear the same potential and/or risks. Additionally, we only discussed a potential implementation since the approach is not implemented yet. While we did a first analysis on the efficiency, quality, quantity and speed, there is room to address these issues in future research adequately.

Future research might have a look at the longitudinal analysis and evaluation of the application of hybrid intelligence, e.g. through action research.
Additionally, the presented case or similar phenomena might be examined with further design science research approaches in order to extend the body of knowledge on deploying hybrid intelligence in a utility-seeking manner to shape the future of work.

\section{Conclusion}

Overall, our results provide deeper insights into the design of hybrid intelligence systems. It is the goal of this paper to present how hybrid intelligence should be designed to open the black box of royalties within the music industry. To design our artefact, we seized a DSR approach. In that, based on the analysis of literature and a total of ten semi-structured interviews with users we both deductively and inductively formulated a concise set of four design features hybrid intelligence systems that shall enhance value capturing within the music industry. The conducted literature review reveals multiple fields of action and areas of improvement. The identification and analysis of the issues within the particular industry of interest are essential for the understanding of the implementation and adoption of hybrid intelligence from research as well as a practical viewpoint. This pinpoint leads to the identified requirements for a hybrid intelligence system. Moreover, we presented a concept-oriented initial instantiation of a hybrid intelligence system and evaluated our design requirements of our alpha version with expert interviews in the field of music production. Further, our analysis demonstrated how humans and machines might complement each other in the future. By developing a first proof of concept of how hybrid intelligence can potentially lead to a shift in value creation in the music ecosystem, we intend to spark and guide the discussion on the various use case scenarios of hybrid intelligence among both researchers and practitioners. Ultimately, this shall pave the way for advancing research on this emerging phenomenon.

\section{References}

[1] Bain, K., "Tomorrowland 2020 Canceled Due to Coronavirus", Billboard, 2020. http://www.billboard.com/ articles/news/dance/9358949/tomorrowland-2020-canceleddue-to-coronavirus

[2] Bellman, R., An introduction to artificial intelligence: Can computers think?, Thomson Course Technology, 1978.

[3] Blohm, I., J.M. Leimeister, and H. Krcmar, "Crowdsourcing: how to benefit from (too) many great ideas", MIS Quarterly Executive 12(4), 2013, pp. 199-211.

[4] Cashmore, P., "Prince is on Spotify but Taylor Swift, Thom Yorke and Beyoncé are holding out", The Guardian, 2017. https://www.theguardian.com/technology/shortcuts 
/2017/feb/15/prince-is-on-spotify-but-taylor-swift-thomyorke-and-beyonce-are-holding-out

[5] Christman, E., "How Much Money Is There in Unclaimed Black Box Royalties?", Billboard, 2019. http://www.bill board.com/articles/business/8517816/unclaimed-black-boxroyalties-how-much-money

[6] Coscarelli, J., "Coachella and Stagecoach Canceled as Officials Fear Virus Resurgence", The New York Times, 2020.

[7] Dellermann, D., P. Ebel, M. Söllner, and J.M. Leimeister, "Hybrid Intelligence", Business \& Information Systems Engineering 61(5), 2019, pp. 637-643.

[8] Döring, N., and J. Bortz, "Forschungsmethoden und Evaluation", Wiesbaden: Springerverlag, 2016.

[9] Gervais, D., Collective management of copyright and related rights, Kluwer Law International BV, 2015.

[10] Glaser, B.G., and A.L. Strauss, Discovery of grounded theory: Strategies for qualitative research, Routledge, 2017.

[11] Gregor, S., and A.R. Hevner, "Positioning and presenting design science research for maximum impact", MIS quarterly, 2013, pp. 337-355.

[12] Gregor, S., and D. Jones, "The anatomy of a design theory", Association for Information Systems (2007).

[13] Hale, K., "Jay-Z's Return To Spotify Could Be The Nail In Tidal's Coffin", Forbes.

[14] Hevner, A.R., "A three cycle view of design science research", Scandinavian journal of information systems 19(2), 2007, pp. 4.

[15] Jordan, M.I., and T.M. Mitchell, "Machine learning: Trends, perspectives, and prospects", Science 349(6245), 2015, pp. 255-260.

[16] Kamar, E., "Directions in Hybrid Intelligence: Complementing AI Systems with Human Intelligence.", IJCAI, (2016), 4070-4073.

[17] Kittur, A., J.V. Nickerson, M. Bernstein, "The future of crowd work", Proceedings of the 2013 conference on Computer supported cooperative work, (2013), 1301-1318.

[18] Kretschmer, T., and C. Peukert, "Video killed the radio star? Online music videos and digital music sales", CEP Discussion Papers(1265), 2014.

[19] Lindvall, H., "Where did all the money go? It's in the Black Box...", The Guardian, 2008. https://www.the guardian.com/music/musicblog/2008/may/20/anastutebusines ssenseand

[20] Mrass, V., C. Peters, and J.M. Leimeister, "One for All? Managing External and Internal Crowds Through a Single Platform-A Case Study.", 2017.

[21] Nunamaker Jr, J.F., R.O. Briggs, D.C. Derrick, and G. Schwabe, "The last research mile: Achieving both rigor and relevance in information systems research", Journal of management information systems 32(3), 2015, pp. 10-47.

[22] O'Dair, M., "Music on the blockchain: blockchain for creative industries research cluster", Middlesex University Report 1, 2016, pp. 4-24.

[23] PricewaterhouseCoopers, "Global Entertainment \& Media Outlook 2019-2023 - Getting personal: Putting the me in entertainment and media", $P w C$. https://www.pwc.com/ gx/en/industries/tmt/media/outlook.html

[24] Resnikoff, P., "How Streaming Services are Screwing Lady Gaga (and Every Other Artist)", Digital Music News, 2014. https://www.digitalmusicnews.com/2014/06/ 10/streaming-services-screwing-lady-gaga-every-artist/

[25] Sater, S., "Tokenize the musician", Tul. J. Tech. \& Intell. Prop. 21, 2019, pp. 107.

[26] Sitonio, C., and A. Nucciarelli, "The impact of blockchain on the music industry", 2018.

[27] Smith, E., "Unlocking Music Royalties' Black Box' WSJ", 2011. https://www.wsj.com/articles/SB10001424052 970203707504577012253235420394

[28] Solo, A., "The role of copyright in an age of online music distribution", 2014.

[29] Soni, N., "Tracking How Royalties Flow In The Digital Age, And How the MMA Will Play a Role", Billboard, 2018.

[30] Sonnenberg, C., and J. vom Brocke, "Evaluations in the Science of the Artificial - Reconsidering the Build-Evaluate Pattern in Design Science Research", Design Science Research in Information Systems. Advances in Theory and Practice, Springer Berlin Heidelberg (2012), 381-397.

[31] Stone, P., R. Brooks, E. Brynjolfsson, et al., "Artificial Intelligence and Life in 2030. One hundred year study on artificial intelligence: Report of the 2015-2016 Study Panel", Stanford University, Stanford, CA.

[32] Sweney, M., "Shaken it off! Taylor Swift ends Spotify spat", The Guardian, 2017.

https://www.theguardian.com/music/2017/jun/09/shaken-itoff-taylor-swift-ends-spotify-spat

[33] Webster, J., and R.T. Watson, "Analyzing the past to prepare for the future: Writing a literature review", $M I S$ quarterly, 2002, pp. xiii-xxiii.

[34] Wikström, P., and R. DeFillippi, Business innovation and disruption in the music industry, Edward Elgar Publishing, 2016.

[35] Billboard. "Highest-Paid Musicians: Billboard's Top 50 Money Makers List", 2020.

[36] Financial Times. "YouTube and German artists settle acrimonious copyright dispute. Retrieved from, https://www.ft.com/content/046b6608-a02b-11e6-891eabe238dee8e2 